\title{
Research on the experimental performance of gas-fired boiler based on the total heat recovery technology of absorption heat pump
}

\author{
Xujing Zhai ${ }^{1}$, Shoutao Tian ${ }^{1}$, Kelin $\mathrm{Zhu}^{2}$, Pan Huang ${ }^{3}$ and Jin $\mathrm{Yu}^{1}$, Ping Huang ${ }^{4, *}$ \\ ${ }^{1}$ State Grid Xinjiang Economic Research Institute, Urumqi, Xinjiang, 830000, China, \\ ${ }^{2}$ State Grid Xinjiang Electric Power Co., Ltd Wenzhou Power Supply Company, Wenzhou, Zhejiang, 325000, China \\ ${ }^{3}$ State Grid Xinjiang Electric Power Co., Ltd Altay Power Supply Company, Altay, Xinjiang, 836300, China \\ ${ }^{4}$ Cross-strait Tsinghua Research Institute, Xiamen, Fujian, 361000, China
}

\begin{abstract}
Based on an example of a gas-fired boiler for an industrial user in Tianjin, the absorption heat pump technology was used to carry out energy-saving transformation of the above boiler. The actual test was carried out on the gas flow, exhaust gas temperature and other parameters from January 2, 2018 to February 26,2018 . And then, the thermal efficiency of the boiler was analysed. The results show that after the energysaving transformation, the exhaust gas temperature of the gas-fired boiler can be reduced from $140{ }^{\circ} \mathrm{C}$ to about $40{ }^{\circ} \mathrm{C}$, and the overall thermal efficiency of the boiler also rises from $89.5 \%$ to $101.3 \%$, which is $13.2 \%$ higher than that before optimization. According to the economic analysis, the energy-saving reconstruction project can achieve an energy-saving economic benefit of 1.598 million yuan throughout the year, with obvious energy-saving and emission reduction benefits.
\end{abstract}

\section{Introduction}

By the end of 2016, the total urban and rural heating area in northern China is about 20.6 billion square meters, of which the urban central heating area is about 14.1 billion square meters ${ }^{1}$. At present, urban and rural heating energy is mainly coal-fired, coal-fired heating area (including coal-fired boiler and coal-fired cogeneration) accounts for about $81 \%$ of the total heating area, while gas-fired heating (gas-fired boiler and gas-fired cogeneration) accounts for about $15 \%$. At the same time, the use of coalfired boilers for heating makes severe haze weather continue to appear in the heating season in northern China, which has a serious negative impact on the lives of northern residents. Therefore, the CPC Central Committee and the State Council attach great importance to the winter heating situation in northern China, and launched the "clean heating plan 2017-2021 in winter in northern China" in 2017. In the plan, the relevant "coal to gas" project is proposed to accelerate the increase of the proportion of clean heating. As an important clean energy, natural gas has gradually become the main force of urban and rural heating with the development of China's "west to East Gas Transmission" and other natural gas projects. However, the traditional gas-fired boiler in the process of using the flue gas emission temperature is too high, which not only causes a waste of energy, but also carries part of $\mathrm{NO}_{\mathrm{x}}$ and $\mathrm{SO}_{2}$ gas into the atmosphere, causing environmental pollution. Therefore, this paper mainly focuses on the traditional gas-fired boiler high- temperature flue gas waste heat recovery research, according to the existing absorption heat pump technology, combined with an absorption heat pump project in Tianjin to recover gas-fired boiler flue gas waste heat.

The main component of natural gas is methane, which will generate $\mathrm{H}_{2} \mathrm{O}$ and $\mathrm{CO}_{2}$ after combustion. The flue gas from combustion contains a large amount of water vapour. The calculation shows that the proportion of latent heat of water vapour vaporization in the high calorific value of natural gas at $150{ }^{\circ} \mathrm{C}$ is about $10 \% \sim 15 \%$. With the popularization of natural gas and the decline of natural gas price, the effective recovery and utilization of the latent heat of steam vaporization generated by natural gas combustion is not only of great energy saving significance, but also of great economic significance. In order to effectively recover and utilize this part of energy, some developed countries began to carry out relevant performance research and experimental production for condensing boilers in the last century, and achieved good results ${ }^{2-4}$. In recent years, some scholars and scientific research institutes in China have begun to study this kind of condensing boiler. By means of direct contact heat exchange ${ }^{5}$ or adding condensing heat exchanger ${ }^{6-8}$, this part of heat can be partially recycled. The thermal efficiency of condensing boiler is about $5 \sim 15 \%$ higher than that of conventional gas boiler.

When the gas combustion conditions are different (especially the influence of excess air coefficient), the condensation temperature of water vapour in the flue gas is also different. When the excess air coefficient is 1.0 , the condensation temperature of flue gas is about $59^{\circ} \mathrm{C}$; when

* Corresponding author: huangping@tshny.cn 
other excess air coefficients are used, the condensation temperature of flue gas will be higher. At this time, in the field of heating, especially in the field of district heating, the water supply temperature of heat supply network varies with different heat users, but the return water temperature is generally above $50 \sim 60{ }^{\circ} \mathrm{C}$. The return water in this temperature range cannot realize the effective recovery of the latent heat of water vapour vaporization in flue gas, thus forming a condensing boiler, which cannot be directly applied in the field of district heating.

In 2018, China's natural gas consumption exceeded 280billion cubic meters, of which Beijing consumed about 18billion. It is assumed that 2 billion cubic meters of natural gas is used for boiler heating and flue gas condensation recovery is carried out, which can save 300 million cubic meters of natural gas per year. The current natural gas price in Beijing is about 263 yuan per cubic meter, which can save 789 million yuan per year. Therefore, it can be seen that the recovery of flue gas condensation heat for heating boilers has great economic and social benefits.

\section{Research Status of Waste Heat Recovery of Gas Boiler Flue Gas}

In the traditional gas-fired boiler, there are many ways to recover the waste heat of flue gas, such as using air preheater to recover the waste heat of flue gas. The specific system principle is shown in Fig. 1a. The high temperature flue gas formed after gas combustion first exchanges heat with hot water in the heat exchanger, and the low temperature flue gas is heated into the air in the boiler, so as to preheat the air. When the exhaust gas temperature of the boiler is high, that is, when the residual heat of the flue gas is large, a water heat exchanger is generally added in front of the air preheater, as shown in Fig. 1b. When the water inlet temperature of the added water heat exchanger is lower than the condensation temperature of water vapour in the flue gas, the latent heat in the flue gas can be effectively recovered, so as to improve the efficiency of waste heat recovery in the flue gas.

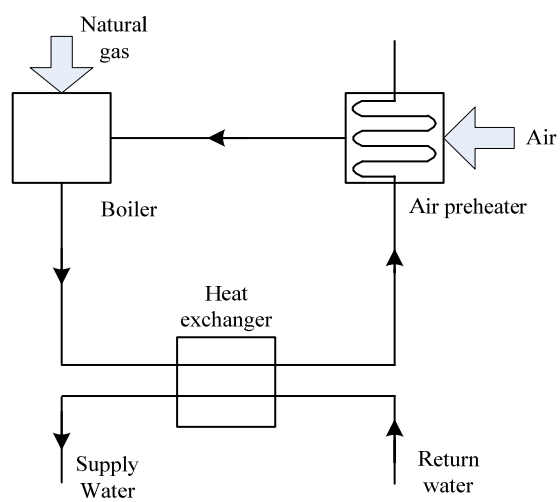

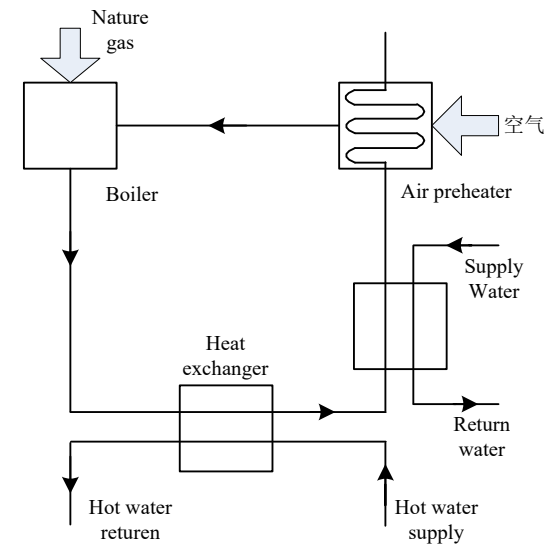

Fig. 1. flue gas waste heat recovery device, A air waste heat recovery system, B waste heat recovery system with additional condensing device

In order to better recover the condensation heat in the flue gas, many scholars at home and abroad began to study the content and characteristics of water vapour in the flue gas, such as using absorption dehumidification technology to recover the latent heat of water vapour in the flue gas, but this technology has the problem of serious corrosion of absorbent (lithium bromide solution), which limits the promotion and application of this technology. In order to solve the above problems, German engineer invented the steam pump flue gas condensation heat recovery system. Although the system solved the corrosion problem, it also brought the problems of high investment and low thermal efficiency ${ }^{9}$.

In order to solve the problems of corrosion and low efficiency at the same time, the absorption heat pump technology $y^{10-12}$ is applied to the condensation heat recovery device of flue gas. The absorption heat pump can absorb low-temperature heat and output high-temperature heat under the drive of high-temperature heat source. This is the first type of absorption heat pump. The specific scheme is shown in Fig. 2. The evaporator of $25{ }^{\circ} \mathrm{C}$ cold water prepared in the absorption heat pump is used to recover the latent heat in the flue gas, that is, the dark blue evaporator in the Fig.2.

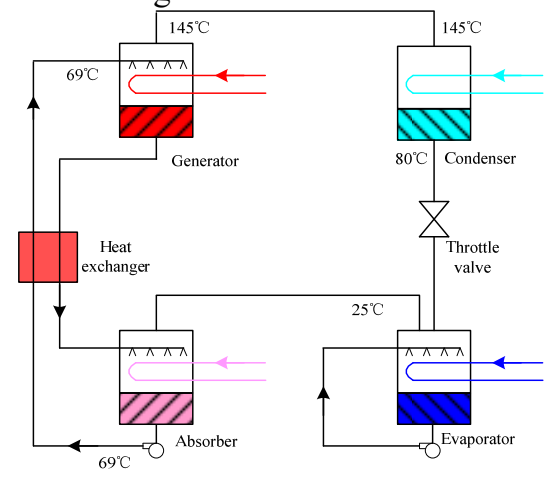

Fig. 2. temperature distribution of fluid at inlet and outlet of absorption heat pump system and equipment

In the absorption heat pump system shown in Fig. 2, the inlet fluid temperature distribution ranges of generator, condenser, evaporator, absorber and other equipment are $69{ }^{\circ} \mathrm{C}, 145^{\circ} \mathrm{C}, 80{ }^{\circ} \mathrm{C}$ and $25^{\circ} \mathrm{C}$, respectively; while the outlet fluid temperature is $145^{\circ} \mathrm{C}, 80^{\circ} \mathrm{C}, 25^{\circ} \mathrm{C}$ and $69^{\circ} \mathrm{C}$, 
respectively. According to the different fluid inlet and outlet temperatures of each component, combined with the gas combustion temperature, flue gas temperature and exhaust gas temperature of the gas-fired boiler system, a variety of schemes to improve the waste heat utilization efficiency of gas-fired boiler can be put forward by combining the two systems.

\section{Introduction of Experimental Engineering}

Based on the energy-saving reconstruction project of a gas-fired boiler in Tianjin, this paper studies the performance of the absorption heat pump to recover the waste heat of flue gas. In this project, the gas-fired boiler is industrial steam boiler, with three sets in total, two for use and one for standby, which runs all year round. The annual steam output of the boiler is about 43000 tons, and the steam outlet pressure is about $0.75 \mathrm{MPa}$. It is mainly used for production process and part of central heating in winter. Before the energy-saving transformation, the flue gas temperature of the boiler changes with the boiler load and weather conditions, mainly distributed between $110^{\circ} \mathrm{C}$ and $160{ }^{\circ} \mathrm{C}$. This part of the flue gas not only contains a lot of sensible heat, but also has a lot of gasification latent heat. After the energy-saving transformation, the outlet flue gas temperature is about $40{ }^{\circ} \mathrm{C} \sim 60{ }^{\circ} \mathrm{C}$. The specific system form after energy saving transformation is shown in Fig. 3.

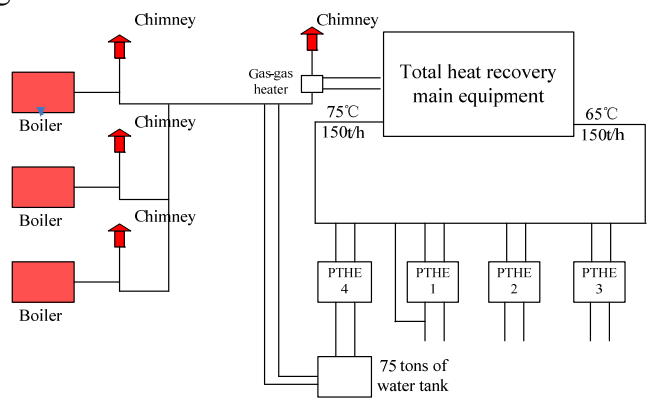

Fig.3. Schematic diagram of energy saving transformation of absorption heat pump

The energy saving transformation project adopts the heat of the gas boiler exhaust and the latent heat of the water vapour. The heating is used for the secondary pipe network water and the residual heat boiler water for $100000 \mathrm{~m}^{2}$ plant heating. On the premise of meeting the normal production process requirements of the factory, the steam heating mode used in the original plant is replaced, so as to save the natural gas consumption and realize energy saving.

It can be seen from Fig. 3 that a set of waste heat recovery equipment is added in the original boiler system in order to recover the waste heat of flue gas as much as possible, improve the utilization rate of equipment, and recover the waste heat with maximum efficiency. Among them, the bypass port is set on the flue gas channel of the original three steam boilers at the same time. By introducing the high-temperature flue gas into the absorption heat pump system, the heat is recovered to meet the heating and hot water needs of the project.
In order to ensure that the waste heat recovery equipment does not affect the original system, the principle of safe bypass is adopted in the process of system transformation. The waste heat recovery equipment is set on the bypass of flue gas and hot water pipe network. When the waste heat recovery system is shut down, the heating and domestic hot water pipes can be switched back to the original pipe section, so as to ensure that the boiler can still maintain normal operation.

As for the energy-saving transformation of the boiler system, the safety bypass pipes on the flue gas side are respectively set on the exhaust pipes of three gas-fired boilers. By setting valves on the bypass pipes, when the waste heat recovery system is working, the above bypass pipe valves are opened to transport the high-temperature flue gas to the waste heat recovery equipment. On the hot water side, the hot water circulation forms a closed loop, and the opening of the regulating valve is also used to control and regulate the hot water required by different loads, so as to prevent the excessive water resistance of the system.

The rated working condition of hot water in the energy-saving transformation system is $65^{\circ} \mathrm{C}$ at the inlet and $75^{\circ} \mathrm{C}$ at the outlet. $75^{\circ} \mathrm{C}$ hot water respectively enters three groups of plate heat exchangers to heat the three heating systems. The hot water inlet is equipped with an electric control valve to meet the heating load of the three heating systems respectively through water volume regulation. The water temperature demand of one heating point may reach more than $70{ }^{\circ} \mathrm{C}$. The energy-saving system has a water mixing bypass at this point. When the water temperature demand is high, the bypass system can improve the heating load Through the waste heat recovery system, the boiler make-up water tank temperature can be increased by $20^{\circ} \mathrm{C}$ every day.

Non heating period: the energy-saving system passes through the plate heat exchanger, the heat source side is $150{ }^{\circ} \mathrm{C}$ flue gas, and the cold side is the boiler make-up water in the water tank. Through the waste heat of flue gas, the temperature difference of the water tank can be increased by $30^{\circ} \mathrm{C}$, and the heated water will continue to be heated by steam, and make-up water for the boiler when it reaches the required temperature.

\section{Energy Saving Analysis}

\subsection{Theoretical Analysis of Boiler Thermal Efficiency}

According to the relevant national standards of gas-fired boiler in China, the calculation of thermal efficiency of gas-fired boiler is based on the low calorific value of gas combustion, and the thermal efficiency of boiler body is:

$$
\eta_{B}=\frac{Q_{2}}{Q_{1}} \times 100 \%
$$

Where, $\mathrm{Q}_{2}$ is the heat effectively utilized by the boiler, that is, the heat absorbed by the water inside the boiler, $\mathrm{kW} ; \mathrm{Q}_{1}$ is the heat released by gas combustion, $\mathrm{kW}$.

When the water vapour in the flue gas discharged from the gas-fired boiler condenses and releases part of the 
latent heat of vaporization, the condensing energy-saving rate of the boiler is as follows:

$$
\eta_{L}=\frac{Q_{3}}{Q_{1}} \times 100 \%
$$

Where: condensation heat released from $\mathrm{Q}_{3}$ flue gas condensation process, $\mathrm{kW}$.

After energy-saving transformation, the overall thermal efficiency of the boiler is the sum of the thermal efficiency of the boiler body and the energy-saving rate of condensation.

$$
\eta=\eta_{L}+\eta_{B}
$$

\subsection{Experimental Test and Analysis}

During the heating period from January 2, 2018 to February 26, 2018, the flue gas temperature of the boiler after the energy-saving transformation is tested. The flue gas temperature test points are set at the outlet of the flue gas boiler and the chimney behind the flue gas heat exchanger, which can realize the test of the flue gas temperature before and after the energy-saving transformation. Firstly, the flue gas temperature at the chimney of the boiler exhaust outlet is tested, and the test results are shown in Fig. 4.

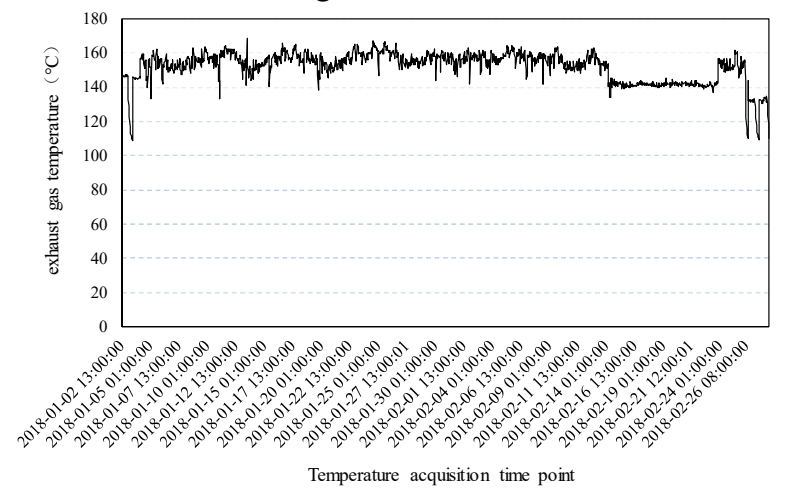

Fig. 4. exhaust gas temperature at the flue gas outlet chimney of boiler

It can be seen from Fig. 4 that at the flue gas outlet chimney of boiler, the exhaust gas temperature is about $140{ }^{\circ} \mathrm{C}$, and the flue gas temperature is higher than the condensation temperature of water vapour in the flue gas, and the water vapour will not condense. If the flue gas is directly discharged to the atmosphere, it will not only lose a lot of sensible heat energy, but also a large amount of latent heat. According to formula (1), the heat efficiency of the boiler under this condition is calculated. It is known that the thermal efficiency of the gas boiler is about $89.5 \%$ by calculation. If the above two parts of heat are recovered, the thermal efficiency of gas boiler can be improved to a certain extent.

According to the energy saving transformation process in Fig. 3, the flue gas exhaust gas will be led to the flue gas heat exchanger through the fan, and the temperature of smoke exhaust gas shall be cooled by the heat exchange between flue gas and cold water. At this time, the flue gas temperature after heat exchange shall be tested in the same way. The test results are shown in Fig. 5.

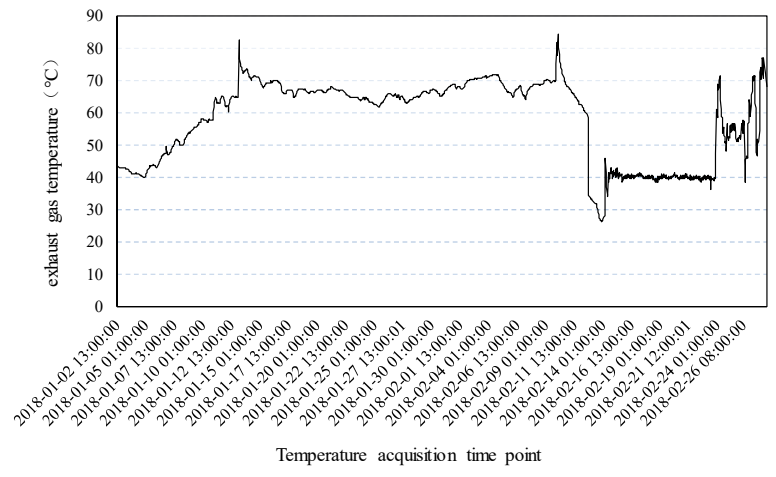

Fig. 5. boiler exhaust gas temperature after energy saving transformation

It can be seen from Fig. 5 that when the energy-saving transformation of the boiler is carried out, the exhaust gas temperature of the boiler changes obviously. At this time, the exhaust gas temperature drops from $140{ }^{\circ} \mathrm{C}$ to about $50{ }^{\circ} \mathrm{C}$, and the sensible heat in the flue gas has been recovered. At this time, the condensation temperature of the flue gas is about $59{ }^{\circ} \mathrm{C}$, and the exhaust gas temperature of the flue gas can be partially reduced to about $50{ }^{\circ} \mathrm{C}$, which can realize the recovery of part of the condensation heat in the flue gas, so as to improve the efficiency of the gas boiler The overall thermal efficiency of the furnace. At this time, due to the condensation of water vapour in the flue gas, the formed condensate adheres to the heat exchange wall, dissolves and absorbs the dust particles contained in the flue gas, as well as other harmful gases such as $\mathrm{NO}_{\mathrm{x}}$ and $\mathrm{SO}_{2}$, thus realizing the purification and emission reduction efficiency of the flue gas. According to the formula $(1) \sim(3)$, the thermal efficiency of gas-fired boiler has reached $101.3 \%$, which is $13.2 \%$ higher than that before optimization.

It can also be seen from Fig. 5 that the flue gas temperature changes greatly before and after the energysaving transformation of the boiler. For example, before February 13, 2018, the flue gas temperature is mainly about $60{ }^{\circ} \mathrm{C}$, and after a period of time, the flue gas temperature drops rapidly to about $40^{\circ} \mathrm{C}$, which is mainly related to the gas flow during the test period, and the variation law of the gas flow during the test period is shown in Fig. 6.

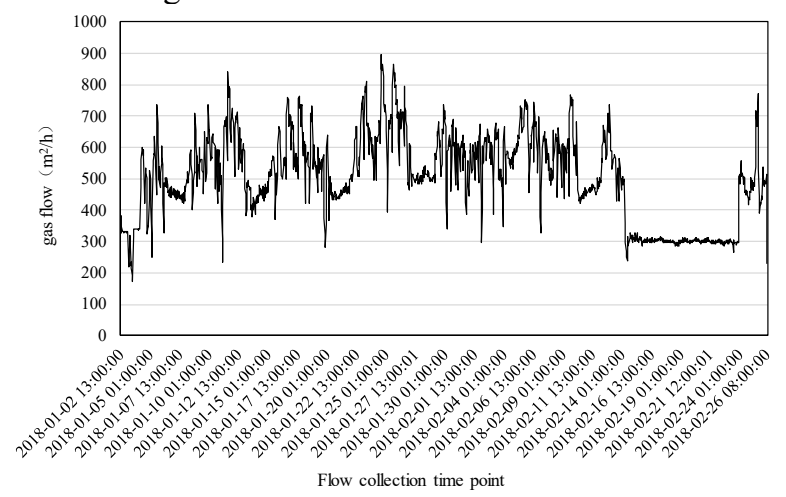

Fig. 6. gas flow variation diagram of gas fired boiler

It can be seen from Fig. 6 that the gas flow changes with the different working conditions of gas-fired boilers. 
Due to the change of gas flow, the flue gas temperature of the boiler also changes. It can be seen that before February 13, 2018, the flue gas temperature and gas flow show similar change rules. After that, with the decrease of gas flow, the flue gas temperature also changes. When the gas flow is small, the water vapor in the flue gas formed after gas combustion can be condensed better, and the generated condensed water is attached to the heat exchange wall. On the one hand, it can transfer the latent heat of water vapor to the refrigerant medium, and on the other hand, the condensed water can also absorb and dissolve some harmful impurities and gases such as dust particles, $\mathrm{NO}_{\mathrm{x}}$ and $\mathrm{SO}_{2}$ in the flue gas, so as to realize the energy saving and emission reduction of gas-fired boiler characteristic.

\section{Conclusion}

1. The absorption heat pump waste heat recovery energysaving transformation is carried out for the gas-fired boiler in this paper. The exhaust gas temperature of the gas-fired boiler is reduced from $140{ }^{\circ} \mathrm{C}$ to $40{ }^{\circ} \mathrm{C}$, and the thermal efficiency is effectively improved, reaching $101.3 \%$, with a relative increase of $13.2 \%$.

2. When the flue gas temperature drops to about $40^{\circ} \mathrm{C}$, the water vapor in the flue gas condenses. On the one hand, it can improve the thermal efficiency of the gas-fired boiler. Similarly, the condensing type formed after the condensation of the water vapor can also absorb the dust and harmful gases in the flue gas, such as $\mathrm{NO}_{\mathrm{x}}$ and $\mathrm{SO}_{2}$, and realize the reduction of the pollutant concentration in the flue gas.

3. The gas-fired boiler after energy-saving transformation achieves $13.2 \%$ energy-saving rate. In this project, there are three industrial steam boilers, two for use and one for standby. The annual steam output of the boiler is about 43000 tons. Calculated according to the lowtemperature calorific value of natural gas, the total annual gas saving is about $504000 \mathrm{~m}^{3}$. According to the natural gas price of Tianjin from 2019 to 2020 , it is 3.17 yuan/ The energy saving economic benefit of 1.598 million yuan can be achieved in the whole year.

\section{References}

1. J. Wang, J. Hua, L. Fu, Z. Wang and S. Zhang, Energy, 2019, 956-970.

2. L. Feng, D. Lin, F. Lin and Z. Xiling, Science and Technology for the Built Environment, 2019, 25, 149155.

3. D. T. Bălănescu and V. M. Homutescu, in Procedia Manufacturing, 2019, pp. 504-512.

4. S. K. Ziganshina and A. A. Kudinov, in J. Phys. Conf. Ser., 2018.

5. J. Hinrichs, D. Felsmann, S. Schweitzer-De Bortoli, H. J. Tomczak and H. Pitsch, Applied Energy, 2018, 229, 977-989.

6. C. Esarte and J. Delgado, Energy and Fuels, 2018, 32, 10106-10113.

7. D. T. Bălănescu and V. M. Homutescu, Applied
Thermal Engineering, 2018, 143, 48-58.

8. C. VanWormer and D. Grassl, ASHRAE Journal, 2018, 60, 18-27.

9. W. Cao, F. Liu and X. Y. You, Heat Mass Transfer, 2018, 54, 1951-1960.

10. P. Christodoulides, L. Aresti and G. Florides, Applied Thermal Engineering, 2019, 158.

11. C. Blackman, K. R. Gluesenkamp, M. Malhotra and Z. Yang, Applied Thermal Engineering, 2019, 421432.

12. K. T. Papakostas and F. Pitsavou, in IOP Conference Series: Materials Science and Engineering, 2018. 